\title{
Commentary
}

\section{Ethics and evidence based research: Is there a conflict?}

thics is a well-known entity, which though not $\checkmark$ measurable has great value in every profession more so when we strive for evidence based research. The correlation between ethics and research practices is interesting and well-thought of in the present scenario for research practices.

Ethics is basically a philosophical term for professional values and it is eternal. Every human being is supposed to follow ethical practices in every walk of life. Ethics is expected to be followed in medical, dental, nursing, law, teaching, business and every other profession by one and all. Researchers are also supposed to work within the gambit of proven evidence, either scientific or based on experience. The scientific researchers have a greater responsibility to follow the ethical practices as their positive or negative reporting will be followed by billions.

Research is a multifaceted activity. The Merriam-Webster dictionary defines research as 'studious inquiry or examination, especially investigation or experimentation aimed at the discovery and interpretation of facts, revision of accepted theories or laws in the light of new facts, or practical application of such new or revised theories of law' ${ }^{\text {'11 }}$ Research involves on-site work, investigations, case studies or analysis of any activity. Research is designed and performed to prove or evaluate the known or unknown facts based on the literature or experience. It is also performed to prove or disprove one's belief. This belief may or may not have evidence. For example, we developed a lip guard to protect the repaired cleft lip against malrotated incisors. ${ }^{[2]}$ We used tin plate, dental compound, raw plastic sheet and then silicon sheet in the process of evolution of this lip guard. Though, there

\begin{tabular}{|l|l|}
\multicolumn{3}{c|}{ Access this article online } \\
\hline Quick Response Code: & \\
\hline
\end{tabular}

was no evidence in the literature that this lip guard will be useful, but we had belief in our reasoning (level 5 of evidence based medicine [EBM]) and we proved it right by reaching level 4 and then level 3 of EBM. Now one may say that it is not ethical to use tin plate and dental compound as they may be reactive and are likely to cause a reaction in the surrounding tissues. However, in the process of evolution and research these were used as they were available in the given situation, after due informed consent. The positive as well as negative evidences are also published in the journal to make it accessible to the public as required by the Declaration of Helsinki (DOH).

On the other hand, I believe that if one performs only level 2 or level 1 evidence based research, there is no controversy and such research ought to be ethical. The baseline here is previous research or established facts or theory. Hence to my mind, there is very little scope of conflict between evidence based research and ethical practices in research if it is carried out diligently, following the guidelines and all the results are reported truthfully without any bias for and against. However, there could be plenty of scope for conflict between ethics and clinical practices. The DOH outlines the ethical practices in research involving human subjects and these have been amended from time to time, the last in 2008. This leaves little scope for unethical practices in research involving human subjects if we follow it strictly in letter and spirit. The amendments are being carried out for a better understanding of the declaration and for easy implementation. ${ }^{[3]}$ The World Medical Association realised the need for transparency and world-wide availability of evidence in research, thereafter two important amendments have been carried out. The first amendment is every clinical trial must be registered in a publicly accessible database. The DOH emphasises that the authors, editors and publishers all have ethical obligations to publish the results of research, may it be negative or positive. The authors are accountable for the completeness and accuracy of their reports. The results should be made public through a journal and/or internet. They also talk of sources of funding and disclaimers. ${ }^{[4]}$ There cannot be better emphasis on evidence based ethical 
research practices than implementing these amendments not just in words, but also in its spirit. If one follows the DOH guidelines, there cannot be a conflict between ethics and research practices.

Many a times, I, as reviewer and editor of a journal, have noticed that authors mention that while carrying out the study guidelines of DOH have been followed. However, there is no way to check the sanctity of such a statement. Even the journal sites do not carry any link for submission of documentary proof of approval of institute ethical/ research committee. This needs to be incorporated in manuscript submission link. Till then the authors have the responsibility to follow the ethical guidelines and take proper permission and approval from the concerned authorities before the research is carried out.

Meanwhile, Indian Council of Medical Research (ICMR) has also published their ethical guidelines for conducting biomedical research involving human subjects. These are exhaustive guidelines and have covered almost every issue, which could be considered during research planning and execution. These guidelines deal with general ethical issues on research, e.g., consent, conflict of interest, compensation, confidentiality, international collaboration/assistance, relationship with media, and publication. ICMR has also given guidelines on drug/ vaccine/herbal remedy trials, epidemiological studies, human genetics, genomic research, tissue transplant, and much more. It is a very important reference publication of ICMR..$^{[5]}$ These ethical guidelines are strictly implemented in research projects under ICMR. However, it might become a law in future for other researches in the country. The Medical Council of India, the supreme governing body of Indian medical fraternity also emphasises that all medical research in India must follow the ICMR guidelines. Any violation in this regard will be considered as misconduct. ${ }^{[6]}$

'Ethics and evidence based research-is there a conflict?' is an impressive and thought provoking editorial. To my mind surgical researchers have to face ethical dilemmas many a times. One is the ethics of clinical research as per $\mathrm{DOH}$ and the other is the ethics of clinical practice dictated by financial and circumstantial considerations. One has to balance the tripod of research methodology, research ethics, and ethics of health-care. The balancing of these three is not an easy task. Many of us compromise on one or the other usually unknowingly. The author has given many pertinent examples proving my point of view. This is also a good attempt to remind the readers about the need to follow a code of conduct while designing a research. The author must be congratulated for analysing the role of $\mathrm{DOH}$ relevant to plastic surgery and making an attempt to explain the EBM and relevant part of DOH. A periodic reminder of research practices is a positive attempt to improve the research practices amongst the readers. This will definitely improve the quality of research in plastic surgery and ultimately the quality of publications in the journal.

\section{ACKNOWLEDGMENT}

The authors thank Dr. Aparna Agrawal, MD, Director Professor LHMC and Associated Hospitals, New Delhi for her suggestions, editing, and correction of English transcript.

\section{Karoon Agrawal}

Department of Burns, Plastic and Maxillofacial Surgery, VM Medical College and Safdarjang Hospital, New Delhi, India

Address for correspondence: Dr. Karoon Agrawal, Department of Burns, Plastic and Maxillofacial Surgery, VM Medical College and Safdarjang Hospital, New Delhi - 110 029, India. E-mail: karoonaparna@gmail.com

\section{REFERENCES}

1. Available from: http://www.merriam-webster.com/dictionary/ research. [Last accessed on 2013 Apr 15].

2. Agrawal K. A lip guard to protect repaired unilateral cleft lip in adults. Plast Reconstr Surg 1993;91:1163-5.

3. Giordano S. The 2008 Declaration of Helsinki: Some reflections. J Med Ethics 2010;36:598-603.

4. Williams JR. The Declaration of Helsinki and public health. Bull World Health Organ 2008;86:650-2.

5. Ethical guidelines for biomedical research on human participants. New Delhi: ICMR; 2006. Available from: http://www.icmr.nic.in/ ethical_guidelines.pdf. [Last accessed on 2013 Apr 25].

6. Code of ethics regulations, 2002. Medical Council of India notification. http://www.gujhealth.gov.in/images/pdf/legis/indianmedical-council-professional-conduct-2002.pdf. [Last accessed on 2013 May 25].

How to cite this article: Agrawal K. Ethics and evidence based research: Is there a conflict?. Indian J Plast Surg 2013;46:9-10.

Source of Support: Nil, Conflict of Interest: None declared. 